\title{
Effect of Sintering Temperature on Microstructure and Hardness of SiC and Fly Ash Reinforced Copper Matrix Composite
}

\author{
P. Balamurugan, M. Uthayakumar
}

\begin{abstract}
Copper based composites with $\mathrm{SiC}$ and Fly ash as reinforcement is prepared by powder metallurgy process. During processing of composites the compaction pressure is maintained as 400MPa for all combination of materials. The prepared green compacts were sintered on both $700^{\circ} \mathrm{C}$ and $900^{\circ} \mathrm{C}$ and the results microstructure and hardness obtained through Brinell harness test were compared.
\end{abstract}

Keywords: copper, Fly ash, Powder Metallurgy, SiC.

\section{INTRODUCTION}

$\mathrm{C}$ opper is having many good characteristics like high electrical conductivity and thermal conductivity[1]. Copper is preferred over aluminium because of its better conductivity and superior strength at elevated temperatures. Since copper is the soft and ductile material, resistance to wear is relatively lower, which limits its applications in automotive sector without any reinforcement addition. Wear resistance is the mainly dependent upon hardness. To increase the wear resistance, dispersoids contains carbides and oxides such as $\mathrm{SiC}$ [2], $\mathrm{B}_{4} \mathrm{C}$ [3] and $\mathrm{Al}_{2} \mathrm{O}_{3}$ [4] are added to the soft matrix which increases the hardness of the material. Powder metallurgy is the most preferable method and also versatile in nature for producing metal matrix composites because of its less probability toward particle separation compared to stir casting, in which particle separation is major problem when the difference in density between the matrix and the reinforcement material is large. In recent times low cost reinforcement play a major role in the production of composites to reduce the overall cost of the product to compete in the global market. Fly ash is one such low cost can be preferred over the conventional oxide based reinforcements such as alumina and silica, since it is less expensive when compared to conventional oxide based ceramic reinforcements. Studies by various researchers revealed that the addition of the fly ash improved properties such as in tensile/compression strength, hardness and wear resistance when it is added with metal matrix [5], [6].

Revised Manuscript Received on December 5, 2019

* Correspondence Author

P. Balamurugan*, School of Automotive and Mechanical Engineering, Kalasalingam Academy of Research and Education, Krishnankoil, India. Email: pbala.klumech@gmail.com

M. Uthayakumar, School of Automotive and Mechanical Engineering, Kalasalingam Academy of Research and Education, Krishnankoil, India. Email:uthaykumar@gmail.com reinforcement which is abundantly available in India. Fly ash

Processing parameters such as compaction pressure, sintering temperature and sintering time will significantly affect the properties of the composite. Wang [7] reported the increase in closure of surface interconnected pores with the increase in compaction pressure. Increase in temperature improves the sintering of the material, at the same time heating beyond some limit changes the trend behaviour of the material[8]. In the present study, an attempt is made to prepare a composite with silicon carbide and fly ash as reinforcement in copper matrix.

\section{MATERIALS AND METHODS}

Copper powder (oxford chemicals, India) with $99.7 \%$ purity is used as the matrix material with a bulk density of 8940 $\mathrm{kg} / \mathrm{m}^{3}$. Fly ash obtained from the power plant located near Tuticorin is used as one of the reinforcement material having a bulk density of $890 \mathrm{~kg} / \mathrm{m}^{3}$. As purchased silicon carbide powder with the average particle size of $50 \mu \mathrm{m}$ is used as the secondary reinforcement. Five different types of specimens were prepared as follows: copper with out reinforcement, copper with $5 \%$ (vol.) of fly ash, copper with $5 \%$ (vol.)of fly ash $+5 \%$ (vol.) of SiC, Copper with $10 \%$ (Vol) of SiC, Copper with $10 \%$ (vol.) of fly ash. All combinations of materials are blended manually using mortar and compacted at the compaction pressure of $400 \mathrm{MPa}$. Sintering of the specimens are carried out under two different temperatures such as $700^{\circ} \mathrm{C}$ and $900^{\circ} \mathrm{C}$ in furnace with inert atmosphere. Sintering time was maintained as 2 hours for all the combination specimens. Density is calculated based on the Archimedes principle. Microstructures are studied using optical microscopy. All images are captured at 100x magnification. Potassium dichromate solution is used as the etchant. The specifications of the optical microscope used is shown in the Table - I.

Brinell hardness test with $1500 \mathrm{~kg}$ load is carried out to find the hardness of the material. Dwell time for the test is maintained as 10 seconds. To ensure the behaviour test is repeated 5 times and the average value is represented as Brinell Hardness Number(BHN) in the result. The BHN is calculated based on (1).

$$
B H N=\frac{F}{\frac{\pi}{2} D\left(D-\sqrt{D^{2}-D_{i}^{2}}\right)}
$$

Where $\mathrm{F}$ is the Applied Force

D - Intender Diameter

$\mathrm{D}_{\mathrm{i}}$ - Intendation Diameter 
Table - I. Specifications of the Optical Microscope

\begin{tabular}{|l|l|}
\hline Magnification & $50 \mathrm{X}$ to $1000 \mathrm{X}$ \\
\hline Eyepiece & Paired 15X and 10X \\
\hline Objective & $\begin{array}{l}5 \mathrm{X}, 10 \mathrm{X}, 20 \mathrm{X}, 25 \mathrm{X}, 45 \mathrm{X} \text { 50X and } \\
100 \mathrm{X}(\mathrm{Oil})\end{array}$ \\
\hline Power & 12 Volt, 50Watts Halogen lamp \\
\hline Shaft & X-Y direction with 360 Rotation \\
\hline Polarization & With Polarizer Prism \\
\hline Micro Scale & $\begin{array}{l}\text { Attached with } 0.01 \mathrm{~mm} \text { Occular } \\
\text { scale. }\end{array}$ \\
\hline
\end{tabular}

\section{MATERIALS AND METHODS}

Fig. 1 shows the microstructure of the composite specimens and for the specimens without reinforcement addition sintered (a) $900^{\circ} \mathrm{C}$. Fig. 1a shows the microstructure of the composite with $5 \%$ volume of fly ash sintered at $900^{\circ} \mathrm{C}$. The matrix of the metal matrix composite shows the even distribution of the composite particles namely the fly ash with some voids

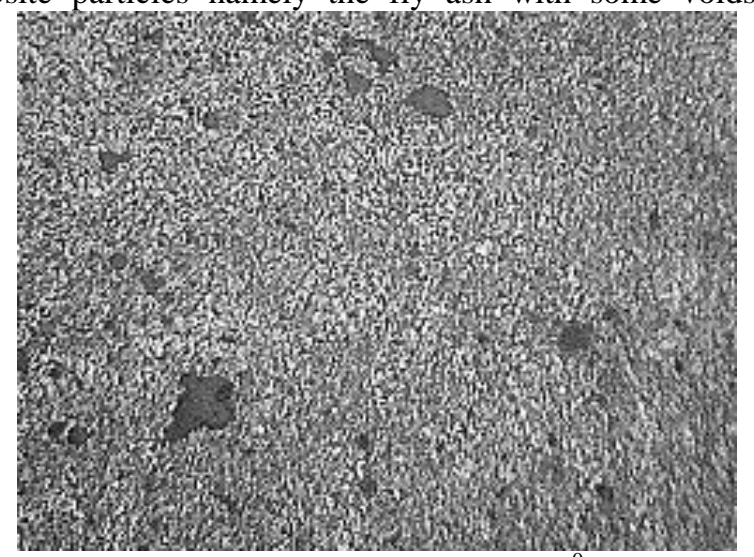

1a. $\mathrm{Cu} 95 \%+\mathrm{FA} 5 \% @ 900^{\circ} \mathrm{C}$

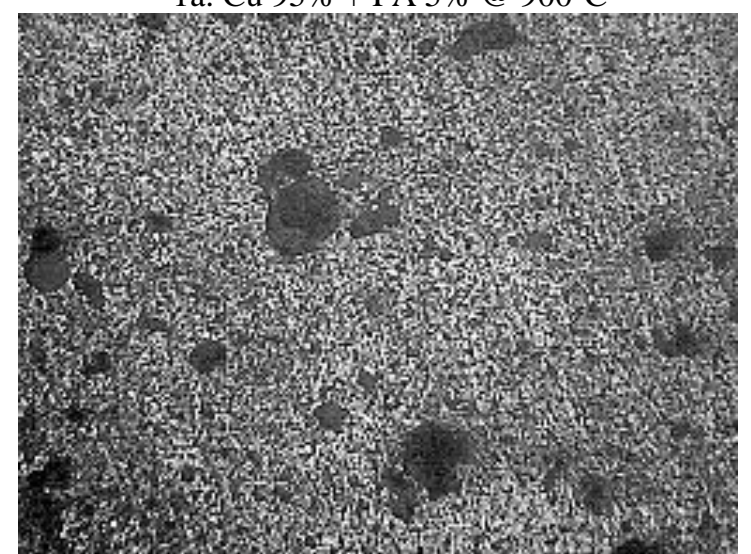

1c. $\mathrm{Cu} 90 \%+\mathrm{FA} 10 \% @ 900^{\circ} \mathrm{C}$ present in the metal matrix. The grains of copper solid solution are so fine in all combinations of specimens as shown in Fig. (1a-1e) and the grain boundaries are cannot be resolved. However, the presence of fly ash in the metal matrix is evenly distributed and can be seen from the dark colored particles. The metal matrix shows homogenous microstructure with fine grains. The higher percentage of fly ash added shows more particles present and distributed in the matrix. The presence of silicon carbide in the metal matrix as shown in figure $1 \mathrm{~b}$ and $1 \mathrm{~d}$ is evenly distributed and can be seen from the dull \& dark colored non spherical long flaky particles. The lower temperature treatment shows coarse grains of copper solid solution which can be identified from Fig. 2. The presence of large number of minor size voids observed in the specimens sintered at $700^{\circ} \mathrm{C}$ compared to specimens sintered at $900^{\circ} \mathrm{C}$. The void gets interconnected and becomes larger at higher sintering temperature.

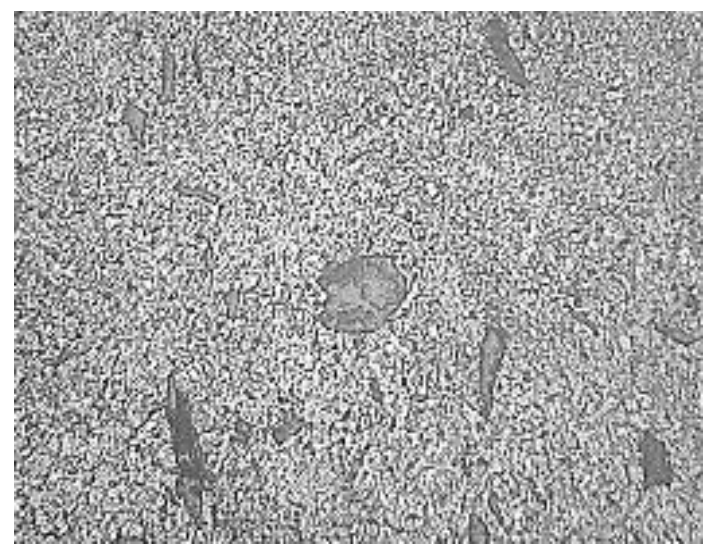

1b. $\mathrm{Cu} 95 \%+\operatorname{SiC} 5 \% @ 900^{\circ} \mathrm{C}$

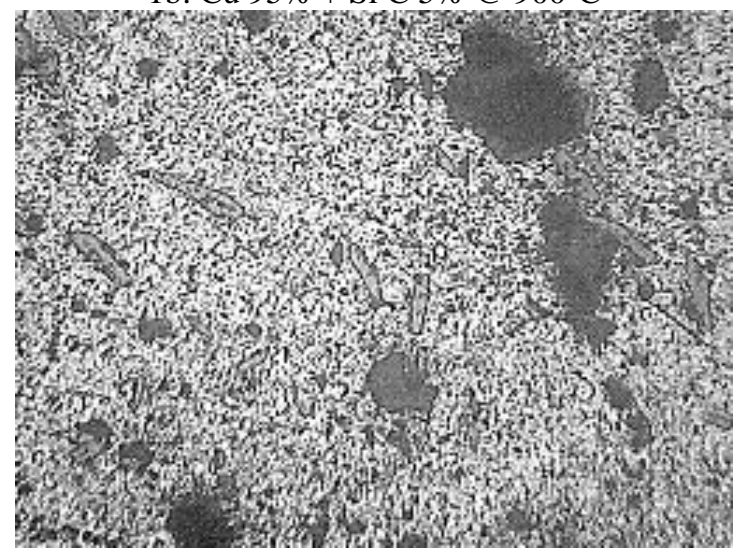

1d. $\mathrm{Cu} 95 \%$ + FA $5 \%+$ Si C $5 \% @ 900^{\circ} \mathrm{C}$

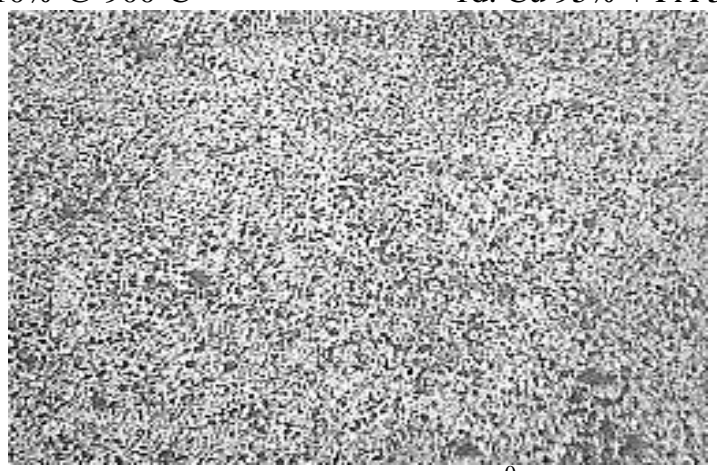

1e. Pure Copper @ $900^{\circ} \mathrm{C}$ 
Fig. 1. Microstructure of pure copper and composites prepared at $900^{\circ} \mathrm{C}$
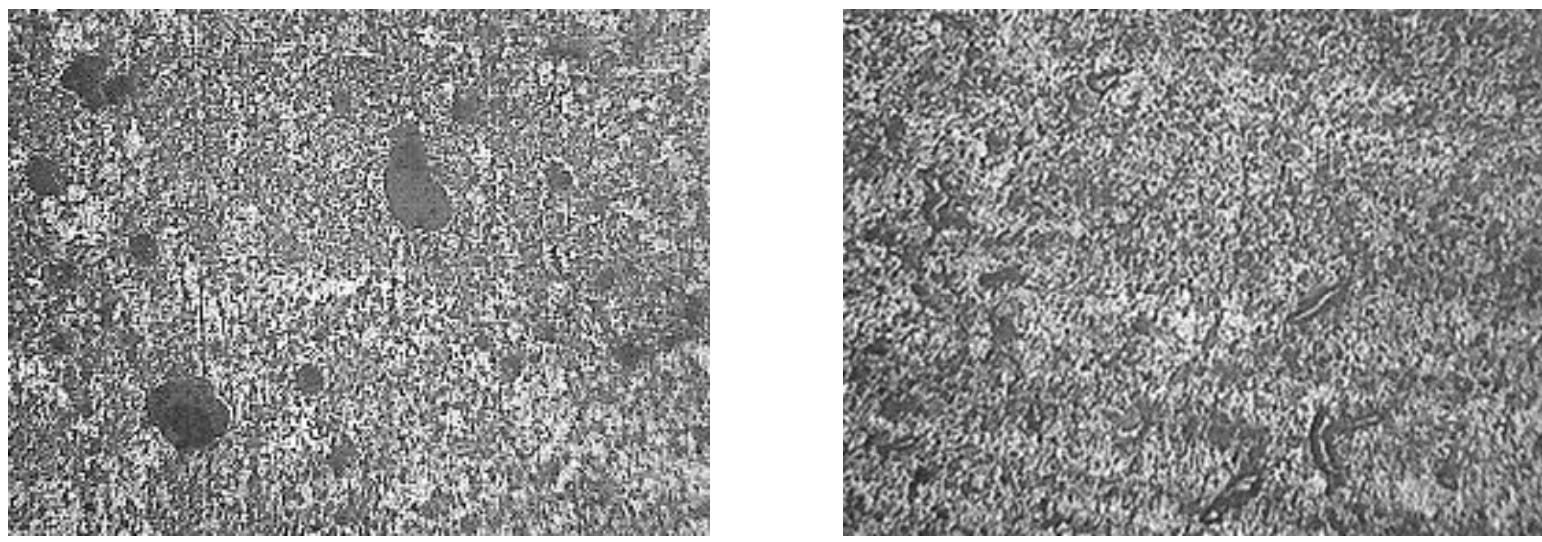

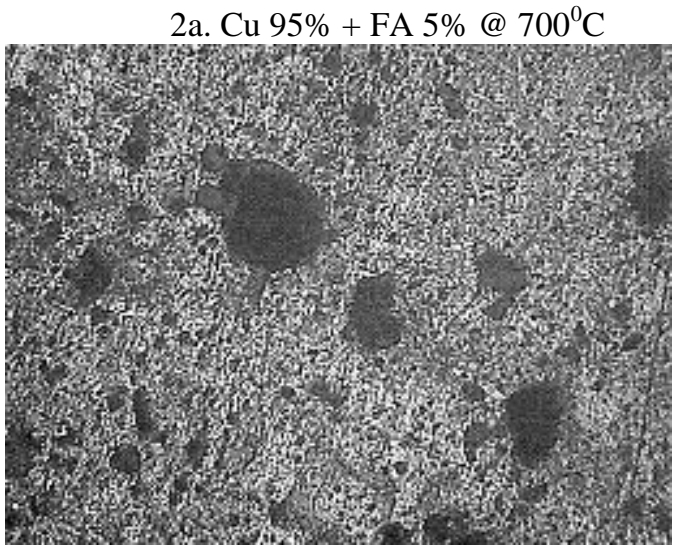

2c. $\mathrm{Cu} 90 \%+\mathrm{FA} 10 \% @ 700^{\circ} \mathrm{C}$ 2b. Cu $95 \%+\mathrm{SiC} 5 \% @ 700^{\circ} \mathrm{C}$

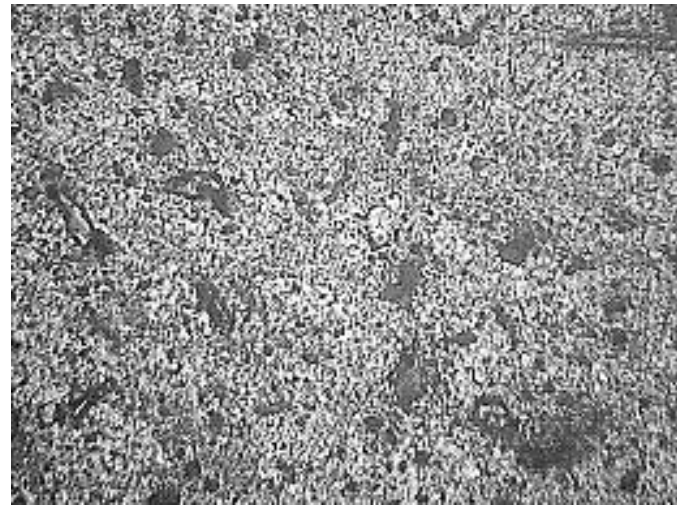

2d. Cu 95\% + FA 5\% + Si C 5\%@700 ${ }^{\circ} \mathrm{C}$

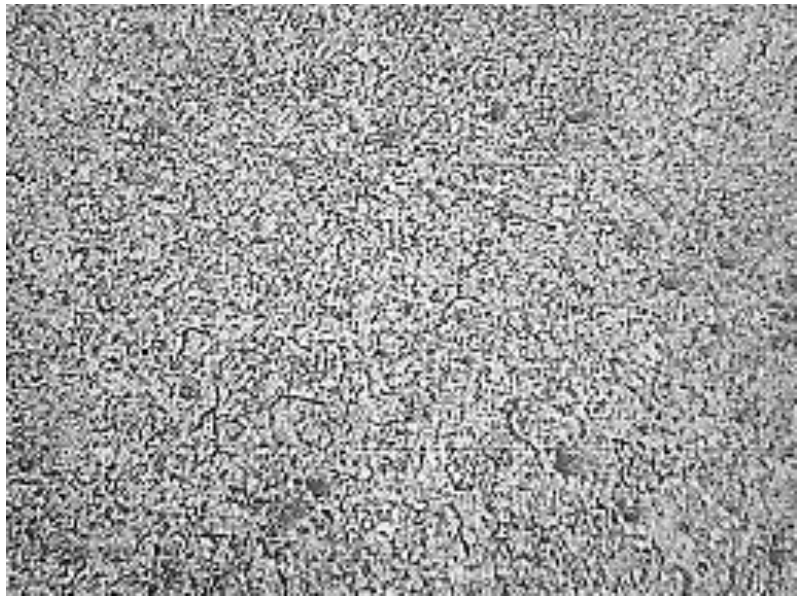

2e. Pure Copper @ 700 $\mathrm{C}$

Fig. 2. Microstructure of pure copper and composites prepared at $700^{\circ} \mathrm{C}$

The hardness of the composite and pure copper sintered at both temperatures is shown in the figure 3. Specimens prepared at $900^{\circ} \mathrm{C}$ is having marginally higher hardness when compared to materials prepared at $700^{\circ} \mathrm{C}$ for all combinations of reinforcement. For the composites with $5 \%$ reinforcement, $\mathrm{Cu}+5 \%$ (vol.) of Fly ash is having higher hardness of $9 \%$ more than the pure $\mathrm{Cu}$ when sintered at $700^{\circ} \mathrm{C}$. At the same time when the sintering temperature is raised to $900^{\circ} \mathrm{C}$ the
$\mathrm{Cu}+5 \%$ (vol.) of $\mathrm{SiC}$ is having higher harness when compared to $\mathrm{Cu}+5 \%$ (vol.) of Fly ash. When the reinforcement content is increased from 5\%(vol.) to $10 \%$ (Vol.), $\mathrm{Cu}+5 \%$ (Vol.) $\mathrm{SiC}+5 \%$ (Vol.) Fly ash is topped with $24 \%$ increase when compared to $\mathrm{Cu}+10 \%(\mathrm{Vol}$.) Fly ash which has the raise in hardness only up to $14 \%$ in comparison with specimen having $0 \%$ reinforcement

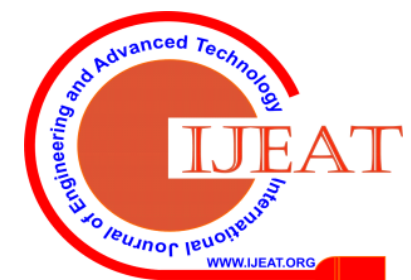




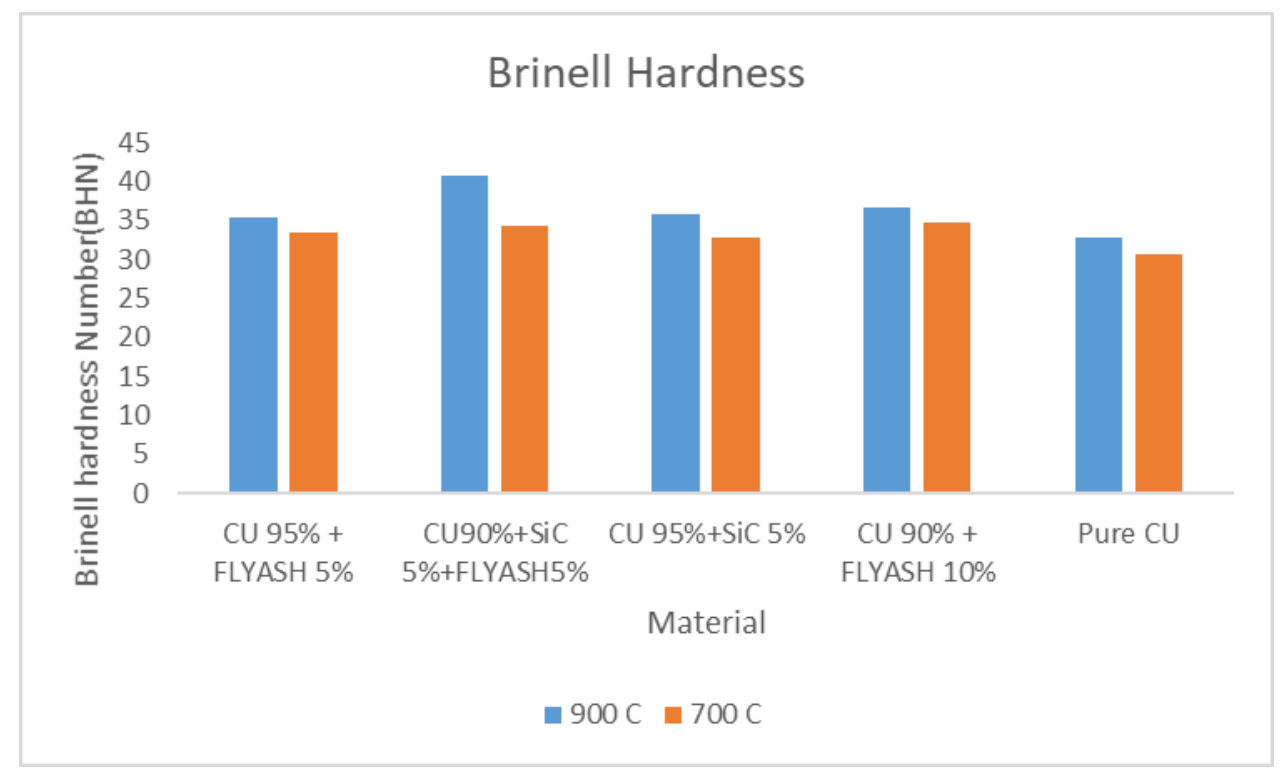

Fig. 3. Brinell hardness of the composites prepared

\section{CONCLUSION}

Four different combinations of composite with fly ash and $\mathrm{SiC}$ as reinforcements was fabricated with two different sintering temperatures were fabricated with fairly uniform reinforcement distribution. Microstructural studies reveal that grain formation is started but smaller for all combination of specimens prepared when the sintering temperature is $900^{\circ} \mathrm{C}$, but no grain formation is noticed when sintered at $700^{\circ} \mathrm{C}$. The sintering temperature plays a significant role in hardness raise, the hardness is raised upto a maximum of $24 \%$ for the composite $\mathrm{Cu}+5 \%$ (Vol.)SiC+5\%(Vol.) Fly ash when sintered at $900^{\circ} \mathrm{C}$

\section{REFERENCES}

1. V. Rajkovic, D. Bozic, A. Devecerski, and M. T. Jovanovic, "Characteristic of copper matrix simultaneously reinforced with nanoand micro-sized Al2O3 particles," Mater. Charact., vol. 67, pp. 129-137, May 2012.

2. G. Celebi Efe, S. Zeytin, and C. Bindal, "The effect of SiC particle size on the properties of $\mathrm{Cu}-\mathrm{SiC}$ composites," Mater. Des., vol. 36, pp. 633-639, Apr. 2012.

3. I. Dinaharan, R. Sathiskumar, and N. Murugan, "Effect of ceramic particulate type on microstructure and properties of copper matrix composites synthesized by friction stir processing," J. Mater. Res. Technol., vol. 5, no. 4, pp. 302-316, 2015.

4. Y. M. Shabana, B. L. Karihaloo, H. X. Zhu, and S. Kulasegaram, "Influence of processing defects on the measured properties of $\mathrm{Cu}-\mathrm{Al} 2 \mathrm{O} 3$ composites: A forensic investigation," Compos. Part A Appl. Sci. Manuf., vol. 46, pp. 140-146, Mar. 2013.

5. N. V. Sai, M. Komaraiah, and A. V. S. R. Raju, "Preparation and Properties of Sintered Copper-Tin Composites Containing Copper Coated or Uncoated Fly Ash," Mater. Manuf. Process., vol. 23, no. 7, pp. 651-657, Sep. 2008

6. P. Balamurugan and M. Uthayakumar, "Influence of Process Parameters on $\mathrm{Cu}-\mathrm{Fly}$ Ash Composite by Powder Metallurgy Technique," Mater. Manuf. Process., vol. 30, no. 3, pp. 313-319, 2015.

7. W. Wang, "Effect of Powder Type and Compaction Pressure on the Density , Hardness and Oxidation Resistance of Sintered and Steam-treated Steels," vol. 16, no. October, pp. 533-538, 2007.

8. X. Xiang, S. Hong-chao, C. Jie, and Y. A. O. Ping-ping, "Effects of sintering pressure and temperature on microstructure and tribological characteristic of Cu-based aircraft brake material," Trans. Nonferrous Met. Soc. China, vol. 17, no. September, pp. 669-675, 2007.

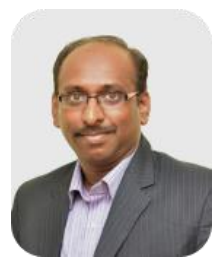

AUTHORS PROFILE

Dr. P. Balamurugan has obtained his Doctoral Degree from Kalasalingam University, India. He is doing research in the area of Characterization, Mechanical, Tribological, Corrosion and erosion studies of metal matrix composites. Currently he is working as Associate Professor in Department of Mechanical Engineering, Kalasalingam Academy of Research and

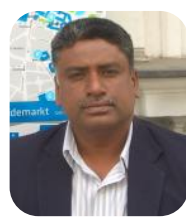
Education, India.

Dr. M. Uthayakumar has obtained Master of Engineering in Production Engineering from Thiagarajar College of Engineering (Autonomous), Madurai, India and Doctorate from Department of Production Engineering, National Institute of Technology, Tiruchirappalli. He has published 145 papers in the international journals and conference. Currently he is a Professor at Department of Mechanical Engineering, Kalasalingam Academy of Research and Education, Krishnankoil, Virudhunagar Dist. 